\section{Kunst und Medizin}

Am 5. Oktober 2010 wurde der Park im Bereich An den langen Lüssen und Grinzinger Allee im 19. Bezirk in Wien nach dem Bildhauer Prof. Hubert Wilfan (1922 bis 2007) benannt und eine Büste - ein Selbstportrait des Künstlers - enthüllt. Hubert Wilfan galt als einer der großen Sakralkünstler und entwickelte eine eigene bildhauerische Technik die Weltgeltung erlangte. Viele Arbeiten im öffentlichen Raum und insbesondere internationale Aufträge zeichneten sein Schaffen aus. In seiner Formensprache drückte er, vor al-

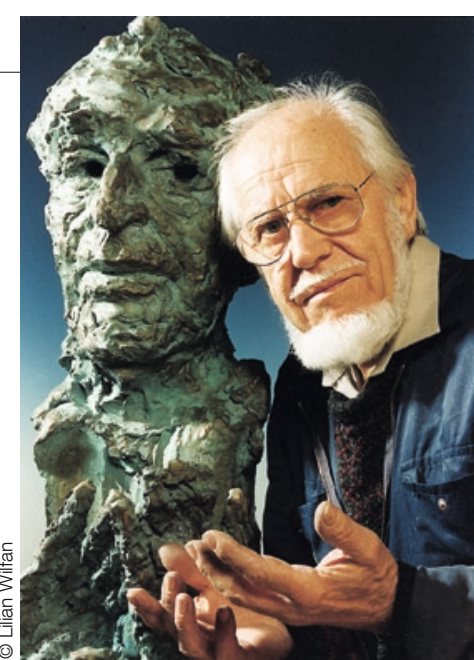

lem in Porträtbüsten, unter anderem von Leonard Bernstein, Marc Chagall, Oskar Werner, Bruno Kreisky, auch psychische Elemente aus. Wilfan engagierte sich zeitlebens sehr für die Thematik Kunst und Medizin und unterstützte Aktivitäten in denen Kunst als Mittler von Gesundheitsbewusstsein und Selbstverantwortung behilflich sein konnte.

Hubert Wilfan mit seiner weltberühmten Marc Chagall Büste 